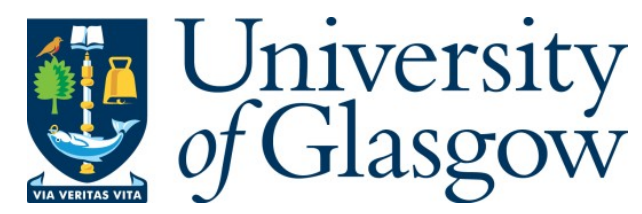

Clark, J. S., Delion, L., and Farrugia, L. J. (2014) Total synthesis of the purported structure of sclerophytin F. Organic Letters, 16 (16). pp. 43004303. ISSN 1523-7060

Copyright @ 2014 A merican Chemical Society

A copy can be downloaded for personal non-commercial research or study, without prior permission or charge

Content must not be changed in any way or reproduced in any format or medium without the formal permission of the copyright holder(s)

http://eprints.gla.ac.uk/96852/

Deposited on: 09 September 2014

Enlighten - Research publications by members of the University of Glasgow http://eprints.gla.ac.uk 


\title{
Total Synthesis of the Purported Structure of Sclerophytin F
}

\author{
J. Stephen Clark ${ }^{*}$, Laetitia Delion and Louis J. Farrugia \\ WestCHEM, School of Chemistry, Joseph Black Building, University of Glasgow, University Avenue, Glasgow, G12 8QQ United \\ Kingdom.
}

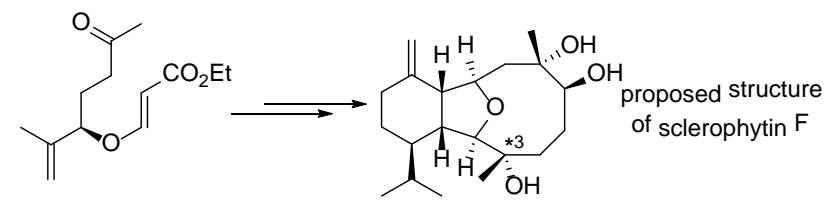

ABSTRACT: The synthesis of the compound that has been proposed to be the natural product sclerophytin F has been completed from a known vinylogous carbonate. The synthetic strategy relied upon rearrangement of a catalytically generated ylide-like intermediate to produce an oxabicyclo[6.2.1]-5-undecen-9-one and an intermolecular Diels-Alder reaction to construct the complete tricyclic core found in the natural product. Comparison of the spectroscopic data for synthetic material to that reported for sclerophytin $\mathrm{F}$ shows that the natural product does not have the revised structure possessing $3 S$ configuration $\left({ }^{*}\right)$ proposed previously.

The sclerophytins are polyoxygenated diterpenes of the cladiellin family of marine natural products. ${ }^{1}$ The first members to be isolated and identified were sclerophytins A and B, which were first reported by Sharma and Alam in $1989 .{ }^{2}$ Sclerophytin A was found to be cytotoxic with activity of $1 \mathrm{ng} \mathrm{mL}{ }^{-1}$ against the L1210 cell line. ${ }^{2}$ Sharma and Alam proposed that sclerophytins A and B were doubly ether-bridged compounds, but subsequent synthetic studies by the groups of Paquette and Overman demonstrated that the originally proposed structures were incorrect and that sclerophytin A is the triol $\mathbf{1}$ and sclerophytin B is the C-6 acetate $\mathbf{2}$ (Figure 1).,

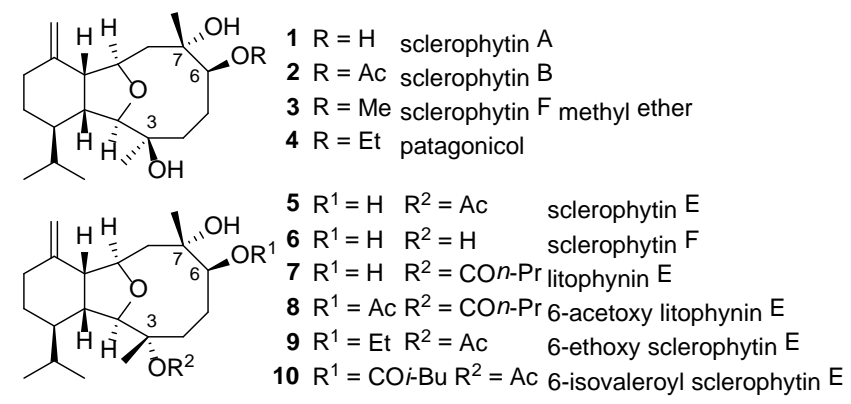

Figure 1. Members of the Sclerophytin Family of Cladiellin Diterpene Natural Products

Several other sclerophytins have been isolated (3-10, Figure 1). ${ }^{5}$ The structures of many of these compounds were deduced by comparison of NMR data to that of sclerophytins A and B, but unfortunately they were predicated on the basis of incorrect structures assigned to sclerophytins A and B by Alam and co-workers. ${ }^{2}$ The exceptions to this are sclerophytin F methyl ether (3) and patagonical (4) (Figure 1), the structures of which were confirmed by X-ray crystallography. ${ }^{5 b, c}$

In an attempt to resolve apparent inconsistencies in the structural assignments for some of the sclerophytins, Friedrich and Paquette reviewed and reanalyzed all of the spectroscopic and other data for these compounds in 2002. ${ }^{6}$ They concluded that there are in fact two series of compounds with opposite stereochemistry at C-3 and reassigned the structures of sclerophytins E and F (5 and 6), litophynin E (7) and the 6-substituted derivatives $(\mathbf{8}-\mathbf{1 0})$ to have $S$ configuration at the C-3 position, as shown in Figure 1.

Sclerophytin F (6) was isolated from the soft coral Sclerophytum Capitalis and identified by Alam and co-workers in 1989 (Figure 1). ${ }^{5 a}$ If the structural reassignments made by Friedrich and Paquette in 2002 are correct, ${ }^{6}$ triol $\mathbf{6}$ is a particularly important compound because it should be possible to prepare all of the other sclerophytins having $S$ configuration at C-3 (5 and 7-10, Figure 1) from this compound. Consequently, scleropythin $\mathrm{F}$ became the primary target in our quest to establish the structures of members of the sclerophytin family of natural products unambiguously by direct synthesis. 
Recently we reported the total syntheses of 10 cladiellin natural products, all of which have $R$ configuration at C-3. ${ }^{7}$ We expected that a parallel synthetic strategy could be developed for the construction of sclerophytin-type cladiellin natural products having $S$ configuration at the C-3 stereocenter. We therefore decided to test our hypothesis by undertaking the total synthesis of the proposed structure of sclerophytin F (6) with the expectation that we would be able access the natural products 5 and 7-10 from the triol thereafter.

The retrosynthetic analysis of the proposed structure of sclerophytin F (6) is shown in Scheme 1. Replacement of the C-6 and C-7 hydroxyl groups with an alkene along with trialkylsilyl protection of the C-3 hydroxyl group gives diene i. Disconnection through the exocyclic alkene and removal of a methyl group from the isopropyl substituent leads to the diketone ii and conversion of the cyclic ketone into an enol ether gives the tricyclic ether iii. Diels-Alder disconnection of the cyclohexenyl ring in iii reveals the bicyclic triene iv. Subsequent disconnection through the conjugated alkoxy diene of iv reveals the bridged-bicyclic ketone $\mathbf{v}$ which in turn suggests the diazo ketone vi as a precursor. Further disconnections of the diazo ketone and the tetrahydropyran then lead to the vinylogous carbonate vii, which is analogous to intermediates used in our previous syntheses of cladiellin natural products. ${ }^{7}$

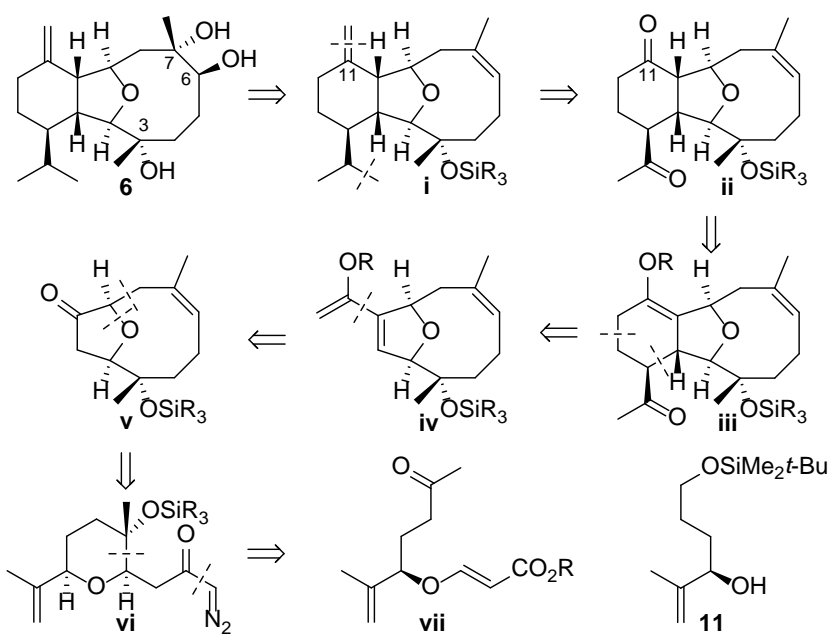

\section{Scheme 1. Retrosynthetic Analysis of Sclerophytin F (6)}

The novelty of the synthetic route implied by the retrosynthetic analysis shown in Scheme 1 stems from the installation of the C-3 methyl substituent at an early stage. In the case of our total syntheses of sclerophytins A and $\mathrm{B}$, which have $R$ configuration at $\mathrm{C}-3$, this methyl group was introduced stereoeselectively at a very late stage in the synthesis. In the proposed synthesis, the C-3 methyl group would be introduced prior to formation and rearrangement of the carbenoid-derived ylide equivalent to deliver the bicyclic ketone $\mathbf{v}$. In adopting this approach, we were aware that intermediates might behave differently in the key reaction, ${ }^{7}$ leading to inferior yields and/or levels of diastereocontrol, and so it might be necessary to deploy completely new transformations to circumvent problems if they were to arise.

The vinylogous carbonate $\mathbf{1 2}$ (91-96\% ee) was prepared in large quantity from the known alcohol 11, as reported previously. ${ }^{7}$ The alcohol 12 was converted into the aldehyde 13 by Swern oxidation (Scheme 2). Treatment of the aldehyde 13 with trimethylaluminium and Swern oxidation of the resulting alcohol delivered the methyl ketone 14. Reductive cyclization of the ketone 14 mediated by $\mathrm{SmI}_{2}$ then furnished an inseparable mixture (12:1) of two diastereomeric (at C-1) tetrahydropyranols, with the required isomer $\mathbf{1 5}$ predominating. ${ }^{8}$ The diastereomers were separated by chromatography following protection of the tertiary alcohol as its $t$-butyldimethylsilyl ether. Sequential ester cleavage, conversion of the carboxylic acid into an anhydride and treatment with diazomethane delivered the key $\alpha$-diazo ketone 17.

The metal-mediated cyclization and ring-expanding rearrangement of the $\alpha$-diazo ketone $\mathbf{1 7}$ to give the isomeric bridged bicyclic ethers E-18 and Z-18 could now be explored (Table 1). In previous work, we had investigated the metal-catalyzed reactions of the tetrahydropyranyl-substituted $\alpha$-diazo ketone lacking a methyl substituent on the ring. ${ }^{7}$ This work had shown that it is possible to tune the reaction to give predominantly the $E$ or $Z$ bridged-bicyclic ether product, resulting from rearrangement of an ylide-like intermediate, by altering the catalyst (ligand and/or metal) or the solvent. ${ }^{9}$ 


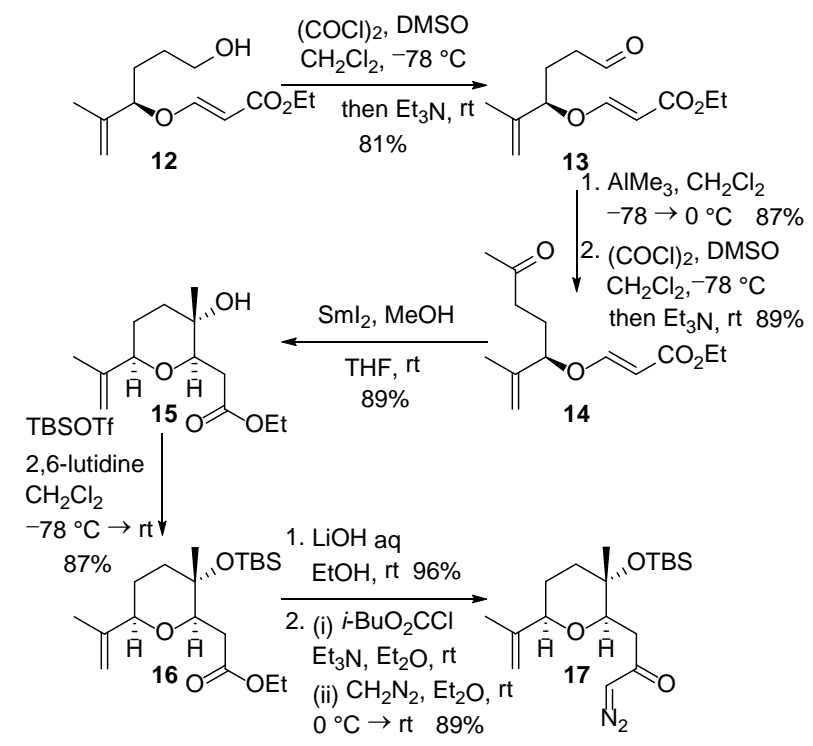

Scheme 2. Synthesis of $\alpha$-Diazo Ketone 17

Table 1. Metal-Catalyzed Conversion of $\alpha$-Diazo Ketone 17 into the Bridged-Bicyclic Ethers E- and Z-18

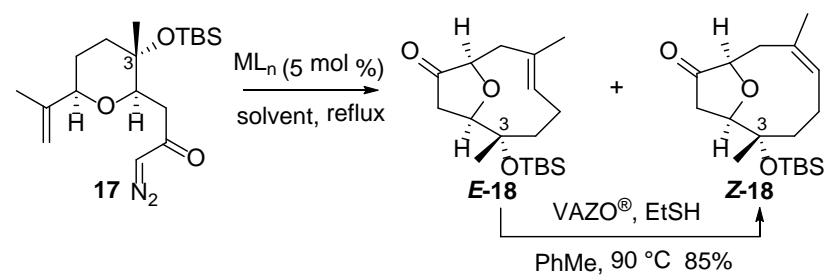

$\begin{array}{ccccc}\text { entry } & \text { catalyst } & \text { solvent } & \text { yield }(\%)^{a} & Z: E \text { ratio }^{b} \\ 1 & \mathrm{Cu}(\text { hfacac })_{2} & \mathrm{CH}_{2} \mathrm{Cl}_{2} & 98 & 1.8: 1 \\ 2 & \mathrm{Cu}(\text { hfacac })_{2} & \mathrm{THF} & 71 & 1: 1 \\ 3 & \mathrm{Cu}(\text { hfacac })_{2} & \mathrm{PhMe} & 49 & 3: 1 \\ 4 & \mathrm{Cu}(\mathrm{acac})_{2} & \mathrm{CH}_{2} \mathrm{Cl}_{2} & - & - \\ 5 & \mathrm{Rh}_{2}(\mathrm{OAc})_{4} & \mathrm{CH}_{2} \mathrm{Cl}_{2} & 42 & 7.9: 1 \\ 6 & \mathrm{Rh}_{2}(\mathrm{tpa})_{4} & \mathrm{CH}_{2} \mathrm{Cl}_{2} & 14 & Z \text { only } \\ 7 & \mathrm{Rh}_{2}(\mathrm{pfm})_{4} & \mathrm{CH}_{2} \mathrm{Cl}_{2} & 61 & 5: 1 \\ 8 & \mathrm{Rh}_{2}(\mathrm{pfm})_{4} & \mathrm{PhMe}_{2} & 31 & 8: 1 \\ 9 & \mathrm{Rh}_{2}(\mathrm{pfm})_{4} & \mathrm{THF} & 31 & Z \text { only }\end{array}$

${ }^{a}$ Combined isolated yield of $\boldsymbol{E}-\mathbf{1 8}$ and $\mathbf{Z}$-18. ${ }^{b}$ Isomer ratios determined by ${ }^{1} \mathrm{H}$ NMR prior to purification. For the Rh-catalyzed reactions, filtration on alumina was done prior to NMR analysis.

Various potential catalysts for the conversion of the $\alpha$-diazo ketone $\mathbf{1 7}$ into the isomeric bridged bicyclic ethers $\mathbf{E}$-18 and Z-18 were investigated and several solvents were also screened (Table 1 ). The catalyst-dependence of the reaction was first probed using a variety of copper and rhodium complexes in dichloromethane at reflux. The best balance between isomer ratio and product yield was obtained when either $\mathrm{Cu}(\mathrm{hfacac})_{2}$ or $\mathrm{Rh}_{2}(\mathrm{pfm})_{4}$ was employed as the catalyst. The use of a non-polar solvent such as toluene resulted in an increase of the isomer ratio (favoring the $Z$ isomer) but this resulted in a significant reduction in yield. An interesting observation was made when the reaction was performed in THF at reflux: the use of the copper catalyst delivered a 1:1 mixture of the products $\boldsymbol{E}-\mathbf{1 8}$ and $\mathbf{Z}$-18, but the $Z$ isomer was obtained exclusively when a rhodium catalyst was employed. However, in this case the product yield for the rhodium-catalyzed reaction was inferior to that of the copper-catalyzed reaction. Interestingly, the highest yielding copper-catalyzed reactions were the least diastereoselective (entries 1 and 2, Table 1), but fortunately it was possible to isomerize the ketone $\mathbf{E - 1 8}$ to give $\mathbf{Z}-\mathbf{1 8}$ using a mixture of VAZO ${ }^{\circ}$ and a substoichiometric amount of ethanethiol in toluene. ${ }^{10}$ In this way, the bicyclic ketone $\mathbf{Z}-\mathbf{1 8}$ was obtained in overall yield of $83 \%$ over two steps without intermediate purification. 
The results from catalyst screening experiments demonstrate that the presence of the methyl substituent on the ring of the substrate $\mathbf{1 7}$ has a profound influence on the stereochemical outcome of the key cyclization reaction. In no case, could the $E$ isomer be obtained as the major product, a finding that contrasts with what had been observed during cyclization of the substrate lacking the methyl substituent on the ring, where the corresponding $E$ isomer could be obtained as the major product simply by using an appropriate rhodium catalyst. ${ }^{7 a}$
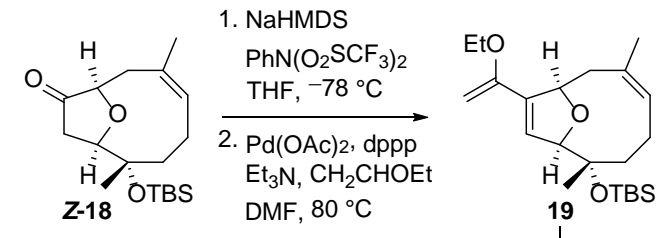

19

MVK, PhMe, $120^{\circ} \mathrm{C}$
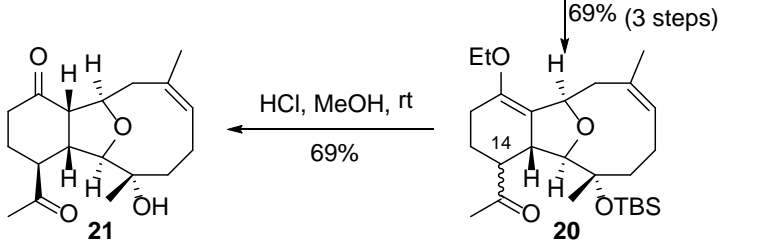

\section{Scheme 3. Construction of the Tricyclic Core}

The next challenge was construction of the complete tricyclic core of sclerophytin F (Scheme 3). To this end, the ketone $\mathbf{Z}$-18 was converted into an enol triflate that was then subjected to Heck coupling ${ }^{11}$ with ethyl vinyl ether to give the diene 19. Intermolecular thermal Diels-Alder cycloaddition of the diene $\mathbf{1 9}$ with methyl vinyl ketone in a sealed tube afforded the tricyclic enol ether $\mathbf{2 0}$ as a mixture (1:1) of exo and endo diastereomers (at C-14). Attempted base-mediated epimerization adjacent to the methyl ketone failed, probably as a consequence of the bulky C-3 silyloxy group blocking access to proton at C-14, and so the TBS protecting group was removed in order to facilitate epimerization. Pleasingly, one-pot hydrolysis of the enol ether, cleavage of the silyl ether and epimerisation at C-14 was observed upon treatment of tricyclic enol ether $\mathbf{2 0}$ with hydrochloric acid. The solid diketone $\mathbf{2 1}$ was obtained as a single diastereomer in good yield and the relative stereochemistry was confirmed by X-ray analysis. ${ }^{12}$

Further functionalization of the tricyclic core structure was necessary to install the required substituents. Selective Wittig methylenation of the diketone was possible, furnishing a separable mixture (5:1) of the methyl ketone $\mathbf{2 2}$ and the double methylenation product $\mathbf{2 3}$ (Scheme 4). Protection of the tertiary alcohol as a TES ether followed by treatment of the methyl ketone with $\mathrm{MeMgCl}$ afforded the tertiary alcohol 24. The hydroxyl group was then removed by acetylation of the alcohol and treatment of the resulting acetate with potassium in presence of [18]crown- 6 and $\mathrm{BBNH}_{2}$ in THF, following a procedure described by Barton and co-workers and used by us and by Kim and co-workers during the synthesis of related cladiellin natural products. ${ }^{7,13}$ Finally, the silyl ether was cleaved under aqueous acidic conditions to deliver the advanced intermediate $\mathbf{2 5}$.

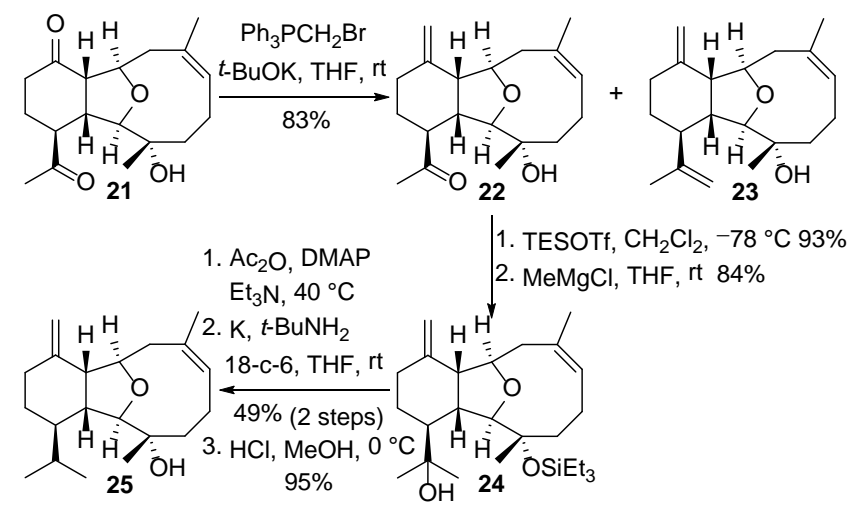

\section{Scheme 4. Synthesis of the Tertiary Alcohol 25}

The oxygen functionality at C-6 was introduced by subjecting the diene $\mathbf{2 5}$ to regioselective and stereoselective epoxidation using $m$ CPBA (Scheme 5). Treatment of the resulting epoxide $\mathbf{2 6}$ with aqueous $\mathrm{H}_{2} \mathrm{SO}_{4}$ resulted in rearrangement to give the allylic alcohol $\mathbf{2 7}$ with $R$ configuration at C-6. ${ }^{14} \mathrm{~A}$ two-step oxidation-reduction sequence was then employed to invert the configuration of the stereocenter at C-6 and deliver the diol having $S$ configuration at this position, as proposed for sclerophytin F. Luche reduction of the enone, produced by DessMartin oxidation of the allylic alcohol 27, delivered a separable mixture (3:2) of diastereomeric alcohols $\mathbf{2 8}$ and $\mathbf{2 7}$. Finally, the C-7 hydroxyl group was introduced by using a Sharpless asymmetric epoxidation reaction to afford the crystalline epoxide 29, the structure of which was 
confirmed by X-ray crystallography (Figure 2). Reductive opening of this epoxide at the terminal position using DIBAL-H then delivered the triol 6, which corresponds to the structure of sclerophytin $\mathrm{F}$ that had been proposed by Friedrich and Paquette. ${ }^{6}$

Although the $[\alpha]_{D}$ for the synthetic triol 6 was in close agreement with that reported for sclerophytin $\mathrm{F}$, the ${ }^{1} \mathrm{H}$ and ${ }^{13} \mathrm{C}$ NMR data for the two compounds were significantly different. ${ }^{15}$ This finding demonstrates that the relative configuration at one or more of the stereogenic centers (C3, C6 or C7) has been reassigned incorrectly by Friedrich and Paquette. ${ }^{6}$
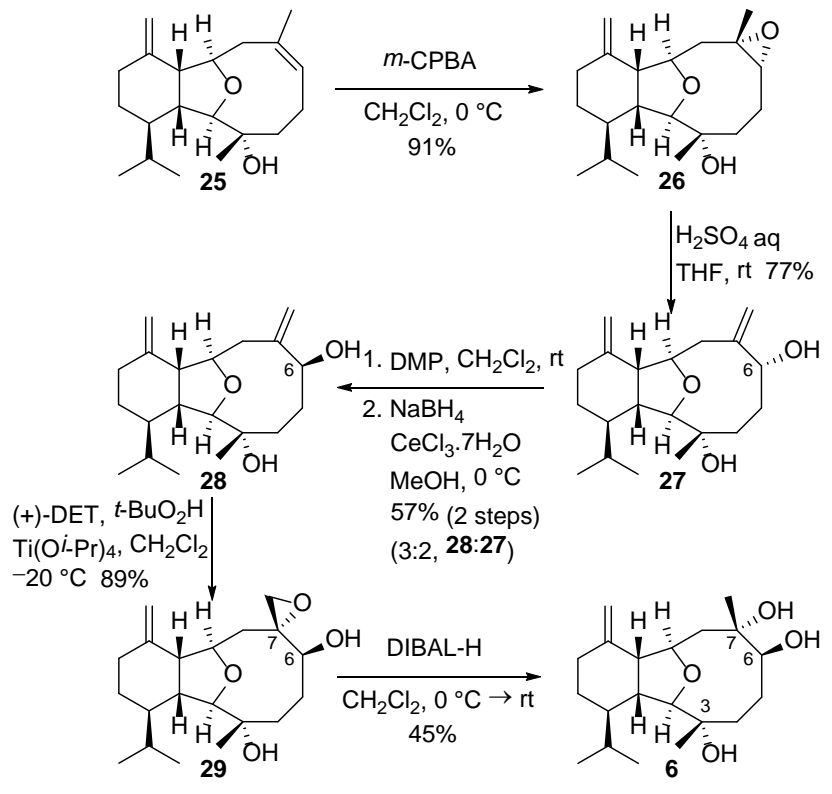

Scheme 5. Completion of the Synthesis of the Proposed Structure of Sclerophytin F (6)

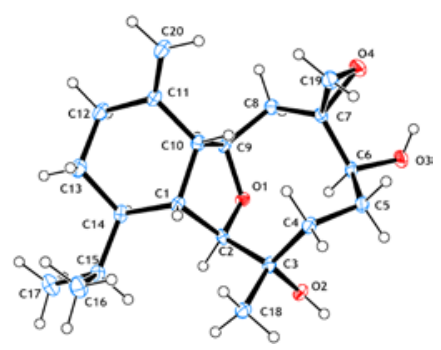

Figure 2. X-Ray Crystal Structure of the Epoxide 29

The first synthesis of the proposed structure of sclerophytin $\mathrm{F}$ has been achieved in 24 steps from the known enantio-enriched alcohol $\mathbf{1 2}$. The strategy developed in our laboratory has now proved to be efficient for the synthesis of cladiellin systems having either $S$ or $R$ configuration at C-3. The introduction of the C-3 methyl group early in the synthesis has influenced several key steps such as the rearrangement of the ylide-like intermediate as well as then epimerisation at the C-14 position. Spectroscopic data for the final triol 6 does not correspond to that reported for sclerophytin $\mathrm{F}$ and so the structure of the natural product proposed by Friedrich and Paquette is clearly incorrect. We are currently in the process of synthesizing the three other triols that are diastereomeric at positions C-6 and C-7. The syntheses of these compounds and their relationship to sclerophytin F will be reported in due course.

\section{Associated Content}

\section{Supporting Information}

Experimental details plus spectroscopic and other data for compounds 14-29 and 6, plus X-ray data (CIF files) for diketone ( \pm )-21, diol 27 and epoxide 29. This material is available free of charge via the Internet at http://pubs.acs.org.

\section{Author Information}

\section{Corresponding Author}

*E-mail: stephen.clark@glasgow.ac.uk.

\section{Notes}

The authors declare no competing financial interest. 


\section{Acknowledgment}

The authors thank the University of Glasgow for studentship funding (LD). We thank Dr. Brian Smith (University of Glasgow) for performing NMR spectroscopy on the triol 6 .

\section{references}

1. (a) Bernardelli, P.; Paquette, L. A. Heterocycles, 1998, 49, 531. (b) Welford, A. J.; Collins, I. J. Nat. Prod. 201 1, 74, 2318.

2. Sharma, P.; Alam, M. J. Chem. Soc., Perkin Trans. 1 1988, 2537.

3. (a) Paquette, L. A.; Moradei, O. M.; Bernardelli, P.; Lange, T. Org. Lett. 2000, 2, 1875. (b) Friedrich, D.; Doskotch, R. W.; Paquette, L. A. Org. Lett. 2000, 2, 1879. (c) Overman, L. E.; Pennington, L. D. Org. Lett. 2000, 2, 2683.

4. (a) Gallou, F.; MacMillan, D. W. C.; Overman, L. E.; Paquette, L. A.; Pennington, L. D.; Yang, J. Org. Lett. 2001, 3, 135. (b) Paquette, L. A. Chem. Rec. 2001, 1, 311. (c) Bernardelli, P.; Moradei, O. M.; Friedrich, D.; Yang, J.; Gallou, F.; Dyck, B. P.; Doskotch, R. W.; Lange, T.; Paquette, L. A. J. Am. Chem. Soc. 2001, 123, 9021. (d) MacMillan, D. W. C.; Overman, L. E.; Pennington, L. D. J. Am. Chem. Soc. 2001, 123, 9033.

5. (a) Alam, M.; Sharma, P.; Zektzer, A. S.; Martin, G. E.; Ji, X.; Van Der Helm, D. J. Org. Chem. 1989, 54, 1896 (sclerophytins C-F). (b) Su, J.; Zheng, Y.; Zeng, L.; Pordesimo, E. O.; Schmitz, F. J.; Hossain, M. B.; van der Helm, D. J. Nat. Prod. 1993, 56, 1601 (patagonicol). (c) Sarma, N. S.; Chavakula, R.; Rao, N.; Kadirvelraj, R.; Row T. N. G.; Saito, I. J. Nat. Prod. 1993, 56, 1977 (sclerophytin F methyl ether). (d) Ochi, M.; Yamada, K.; Futatsugi, K.; Kotsuki, H.; Shibata, K. Chem. Lett. 1990, 19, 2183 (litophynin E and 6-acetoxy litophynin E). (e) Rao, C. B.; Rao, D. S.; Satyanarayana, C.; Rao, V. D.; Kassühlke, K. E.; Faulkner, D. J. J. Nat. Prod. 1994, 57, 574 (6-ethoxy sclerophytin E and 6-isovaleroyl sclerophytin E).

6. Friedrich, D.; Paquette, L. A. J. Nat. Prod. 2002, 65, 126.

7. (a) Clark, J. S.; Berger, R.; Hayes, S. T.; Senn, H. M.; Farrugia, L. J.; Thomas, L. H.; Morrison, A. J.; Gobbi, L. J. Org. Chem. 2013, 78, 673. (b) Clark, J. S.; Berger, R.; Hayes, S. T.; Thomas, L. H.; Morrison, A. J.; Gobbi, L. Angew. Chem. Int. Ed. 2010, 49, 9867. (c) Clark, J. S.; Hayes, S. T.; Wilson, C.; Gobbi, L. Angew. Chem. Int. Ed. 2007, 46, 437.

8. (a) Matsuo, G.; Kadohama, H.; Nakata, T. Chem. Lett. 2002, 148. (b) Clark, J. S.; Hayes, S. T.; Blake, A. J.; Gobbi, L. Tetrahedron Lett. 2007, 48, 2501.

9. (a) Pirrung, M. C.; Werner, J. A. J. Am. Chem. Soc. 1986, 108, 6060. (b) Clark, J. S. Tetrahedron Lett. 1992, 33, 6193. (c) West, F. G.; Naidu, B. N.; Tester, R. W. J. Org. Chem. 1994, 59, 6892. (d) Marmsäter, F. P.; Vanecko, J. A.; West, F. G. Org. Lett. 2004, 6, 1657. (e) Murphy, G. K.; Stewart, C.; West, F. G. Tetrahedron 2013, 69, 2667.

10. Clark, J. S.; Dossetter, A. G.; Blake, A. J.; Li, W.-S.; Whittingham, W. G. Chem. Commun. 1999, 749.

11. (a) Cabri, W.; Candiani, I.; Bedeschi, A.; Penco, S.; Santi, R. J. Org. Chem. 1992, 57, 1481. (b) Cabri, W.; Candiani, I. Acc. Chem. Res. 1995, 28, 2. (c) Andersso, C.-M.; Hallberg, A. J. Org. Chem. 1989, 54, 1502.

12. Crystals of racemic diketone $\mathbf{2 1}$ suitable for X-ray diffraction could be obtained, allowing confirmation of relative stereochemistry. Non-racemic $\mathbf{2 1}$ having high ee did not deliver crystalline material suitable for X-ray analysis.

13. (a) Kim, H.; Lee, H.; Kim, J.; Kim, S.; Kim, D. J. Am. Chem. Soc. 2006, 128, 15851. (b) Barrett, A. G. M.; Godfrey, C. R. A.; Hollinshead, D. M.; Prokopiou, P. A.; Barton, D. H. R.; Boar, R. B.; Joukhadar, L.; McGhie, J. F.; Misra, S. C. J. Chem. Soc., Perkin Trans. 1 1981, 1501.

14. X-ray crystallography confirmed the stereochemistry of the diol 27. See Supporting Information.

15. Differences between ${ }^{13} \mathrm{C}$ NMR data for sclerophytin $\mathrm{F}$ and triol 6 were particularly obvious. The ${ }^{13} \mathrm{C}$ NMR signals reported for the natural product and their deviation from those of triol 6 are as follows: $\left(\mathrm{CDCl}_{3}\right) \delta 147.6(+1.5), 109.3(+1.4), 91.9(+4.9), 86.6(+9.2), 80.1(+4.7), 78.2(+3.1), 77.0$ $(+3.1), 52.9(+5.1), 45.8(+0.6), 45.4(+3.1), 43.9(+3.4), 35.9(+2.7), 31.4(+1.1), 30.5(+0.7), 29.1(-0.3), 24.7(-3.8), 23.2(-1.6), 22.3(-0.4)$, $21.9(-0.3), 15.7(-5.0)$. 